\title{
OECD single-payer policy review
}

Adam Beswick

Faculty Reviewer: Kelly K Anderson, PhD (Department of Epidemiology and Biostatistics)

\section{ABSTRACT}

The Canadian national public healthcare system is federally funded and delivered within provincial and territorial jurisdictions. While this system is a source of national pride, the limitations of this mode of healthcare delivery are an important point of consideration in light of the changing demographic and social factors upon which this system's ongoing economic viability will depend. The Organization for Economic Co-operation and Development aggregates and reports on measures of national health statistics, and therefore provides a valuable point of comparison between Canada and similarly economically developed nations with public healthcare options. A number of salient public policy differences between Canada and other nations are discussed they relate to healthcare delivery. Two broad health policy areas are emphasized as potential areas of improvement with regard to efficient, cost-effective healthcare delivery: access to primary care, and integration of care between primary and specialist services.

\section{INTRODUCTION}

Since the implementation of the Medical Care Act of 1966, Canadians have been justifiably proud of the universal healthcare system in our country. The Canadian single-payer healthcare system, and the tacit implication of national values with which it has been associated, has for many embedded itself into the very identity of what it means to be Canadian.

The Organization for Economic Cooperation and Development (OECD) is an intergovernmental agency that collects economic data among developed nations. ${ }^{1}$ Among the 35 member countries regularly included in its analysis, the Canadian healthcare system stands relatively average as compared to similarly structured single-payer systems. National healthcare spending (\$4608 per capita) is not substantially different than the majority of European, Australian, and South American counterparts. ${ }^{1}$ Among other measures of health outcomes reported by the OECD, the Canadian healthcare system reports falls below the top ten nations in a number of measures, including: life expectancy (79.4 years), percentage of population over the age of 15 who are overweight or obese (52.5\%), and the number of hospital beds per 1000 people (2.7). ${ }^{2}$ Overall, the Canadian single-payer healthcare system is falling behind international best practices. Within the context of healthcare systems delivery, it is therefore imperative to identify both potential areas of improvement.

\section{ACCESS TO PRIMARY CARE}

Access to primary care is an essential component of a robust and economically efficient healthcare system. In Canada, primary care include services such as mental healthcare, palliative and end of life services, health promotion, healthy child development, primary maternity care and basic rehabilitation services. ${ }^{3}$ Overall, the benefits of primary care service in Canada are evident: this form of healthcare delivery is cost-effective, allows patients access to rapid treatment, reduces burden on specialist services, and improves disease prevention and health outcomes for patients. ${ }^{4}$ However, the proportion of Canadians who have access to same-day primary care (41\%) lags behind similar nations like New Zealand (72\%) and Germany (76\%). ${ }^{5}$ This is a consequential reality within the Canadian healthcare system. Patients who do not use primary care are driven to more expensive points of access. For example, a study from Ontario found that over half $(57.4 \%)$ of patients in the emergency department would have chosen to use primary care if it had been available to them. ${ }^{6}$ This problem is not exclusive to Canada, as many single-payer healthcare economies grapple with the issue of "inappropriate" emergency department (ED) use. This is characterized broadly as visits that could otherwise be attended to by community-based primary care services. ${ }^{7}$ However, Canada seems to be unique in the extent to which this problem exists, with a reported $25 \%$ of ED visits in Canada are patients who could otherwise be seen in a primary care setting, as compared to $12 \%$ in the United States, $20 \%$ in Italy ${ }^{4}$, and $15 \%$ in the United Kingdom. ${ }^{8}$

The benefits of improving primary care access are enormous, and healthcare systems that achieve success in this realm realize benefits across a variety of health and economic measures. New Zealand is a global leader in this regard, having entirely restructured their healthcare policy approach to primary care in 2001. The New Zealand government finances all health expenditures for all hospital and specialist care for patients referred by a primary family practitioner. The Primary Health Care Strategy was a program which decentralized healthcare provision from the federal government into the control of 82 District Health Boards (subsequently reduced to 46 in 2008) representing unique districts of the country. ${ }^{9}$ These District Health Boards are composed of elected board members from the communities themselves, and the mandate of the boards is to take the responsibility for their communities' unique needs in an entirely non-profit context. This initiative was widely lauded for its success - today the proportion of New Zealanders with access to primary care is $94 \% .^{10}$

\section{INTEGRATION OF CARE}

In so far as primary care access is an important measure of healthcare system deliverability, integration of specialist care services is an essential component in the continuation of primary care service. Failure to integrate services remains a ubiquitous and 
obstinate barrier to healthcare in Canada. Nowhere is this lack of integration more pronounced than at the junction of primary and specialist care: a 2016 study of primary care physicians in Canada found that $71 \%$ of doctors reported not receiving relevant patient information following a specialist appointment, including changes to patient prescriptions and care plans. ${ }^{11}$ Patients also recognize the lack of integration of care in Canada - a survey of Ontario residents found that $18 \%$ reported that their doctor "did not seem informed" about the care they had received from a specialist appointment. ${ }^{12}$

By virtue of the compartmentalization of service, and without incentive to achieve maximum efficiency in integration of care, it is easy for single-payer healthcare systems to fall victim to healthcare integration problems. The German healthcare system combines public and private insurance for healthcare delivery - with the majority of the population (88\%) accessing healthcare through the public stream. This system of delivery was at the height of inefficiency in the year 2000, where the majority (68\%) of German primary care physicians worked in solo practice, more than $50 \%$ of whom reported that it took more than 14 days to receive full reports of their patients upon discharge from hospital. ${ }^{13}$ Coordination of care with community services such as long-term care, support services, and residential environments for patients with physical or mental deficiencies were criticized as being ineffectual. These failures were largely attributable to disconnected financing streams of the country's medical and social services. In response to these challenges, the German government set a large-scale policy overview with a view to remove inefficiencies and improve integration between primary care, specialist care, and community services. These policies included a number of reforms including improving the gate keeping mandate of primary care physicians within the healthcare system, investing in preventative disease management programs and medical care centers, and developing integrated care contracts - a system through which care is provided within a network of care providers that are overseen by independent management organizations. ${ }^{13}$ German healthcare integration is now regarded as one of the most efficient in the world, $90 \%$ of patients reporting that their primary care physicians were aware of their hospital admission care, as compared to $75 \%$ of patients in Ontario. ${ }^{12}$

\section{CONCLUSION}

It is important to recognize that no healthcare system will ever be perfect. Healthcare delivery is unique in its economic viability it does not follow many of the basic economic assumptions that can be applied to other sectors. Furthermore, every system of healthcare delivery is a microcosm of the demographic, political, economic and social values of a society. That being said, it is important to recognize benchmarks of comparable single-payer healthcare systems in order to generate new ideas to improve Canadian health services. By acknowledging varying provision practices and objectively measuring their success, governments and health advocates can more effectively improve healthcare within our own communities.

\section{REFERENCES}

1. OECD [Internet]. Paris (France); c2017. Health Statistics, Health Status Data Sheet; c2016 [cited 2017 Jan 17]. Available from: http://www. oecd.org/els/health-systems/health-data.htm.

2. OECD [Internet]. Paris (France); c2017. Health Statistics. Health spending (indicator); c2017 [cited 2017 May 23]. Available from: https://data.oecd.org/healthres/health-spending.htm.

3. Canadian Institute of Health Information. [Internet]. c2015. How Canada Compares: Results from the commonwealth fund 2015 International health policy survey of primary care physicians [Press Release]. c2015. [cited 2017 Jan 16]. Available from: https://www.cihi.ca/en/ cmwf/media_release_commonwealth_2015.

4. Canadian Nurses Association. [Internet]. c2012. Evidence Synthesis for the Effectiveness of Interprofessional Teams in Primary Care. Ottawa: Canadian Health Services Research Foundation. c2012. [cited 2017 Jan 16]. Available from: https://www.cnaaiic.ca/ /media/cna/files/en/synthesisinterprofteams_jacobson-en-web.pdf.

5. Kiran T, O'Brien P. 2015. Challenges of same-day access in primary care. Can Fam Physician. 61; 399-400.

6. Wong WB, Edgar G, Liddy C, et al. Survey of ambulatory patients seeking after-hours care. Can Fam Physician. 2009 Nov; 55(11): 1106-1107.

7. McHale P, Wood S, Hughes K, et al. Who uses emergency departments inappropriately and when a national cross sectional study using a monitoring data system. BMC Medicine 2013 Sep; 11:258.

8. Wise J. Most emergency attendances at hospital are appropriate, finds study. BMJ 2014; (348):3479.

9. New Zealand Ministry of Health [Internet], c2017. Overview of Health System. [cited 2017 May 18]. Available from: http://www.health.govt. nz/new-zealand-health-system/overview-health-system.

10. World Health Organization Primary health care the New Zealand. Bull World Health Organ. 2008;86(7): 505-6.

11. Canadian Institute of Health Information [Internet] c2017. Canadian Patient experiences; c2015 [cited 2017 May 23]. Available from: https://www.cihi.ca/en/pia_cper_2015_en.pdf.

12. Health Quality Ontario [Internet] c2017. Emergency department performance in Ontario; c2016. [cited 2017 May 23] Available from: http://www.hqontario.ca/portals/0/Documents/system-performance/ under-pressure-report-en.pdf Accessed Dec 1st, 2016.

13. Schlette S, Lisac M, Blum K. Integrated primary care in Germany: the road ahead. Int J of Integr Care. 2009;9:e14. 